\title{
Demographics, Activity Level, and Shoulder Health History of Populations Participating in CrossFit: A Descriptive Analysis
}

\author{
Skinner $\mathrm{C}^{1}$, Franklin $\mathrm{S}^{2 *}$, Chang J ${ }^{3}$, Sum J ${ }^{2}$, \\ Groshen $\mathrm{S}^{4}$ and Hatch $\mathrm{G}^{5}$ \\ ${ }^{1}$ Houston Methodist Willowbrook Orthopedics \& Sports \\ Medicine, USA \\ ${ }^{2}$ Division of Biokinesiology and Physical Therapy, \\ University of Southern California, USA \\ ${ }^{3}$ Department of Physical Therapy and Rehabilitation \\ Science, University of California, San Francisco, USA \\ ${ }^{4}$ Department of Preventative Medicine, Keck School of \\ Medicine, University of Southern California, USA \\ ${ }^{5}$ Department of Orthopedic Surgery, Keck School of \\ Medicine, University of Southern California, USA \\ *Corresponding author: Samuel Franklin, Divison \\ of Biokinesiology and Physical Therapy, University of \\ Southern California, USA
}

Received: January 30, 2017; Accepted: March 17, 2017; Published: March 24, 2017

\begin{abstract}
Background: CrossFit is a training program that has increased in popularity. The possibility of its association with orthopedic injuries has grown as a topic of discussion in the healthcare industry. Before investigation of this association can begin, baseline descriptive data of the participating population must be available. To date, there is no reported data regarding demographics, activity level, or shoulder heath of CrossFitters.
\end{abstract}

Objective: To describe the demographics, current and previous level of activity, and shoulder health history of people who apply to train at CrossFit gyms Methods: Subjects were recruited from a single CrossFit gym and were asked to fill out the Pre-Participation Questionnaire (PPQ), the Disability of the Arm Shoulder and Hand (DASH), and the Penn-Shoulder Score (PSS).

Results: Seventy nine subjects , ... males (\%), average age $31.15 \pm 7.91$ years, height $1.68 \pm 0.11$ meters, weight $72.60 \pm 13.85$ kilograms and body mass index (BMI) $25.61 \pm 4.08$ participated in the study. The mean intake scores for the DASH and PENN were $2.46 \pm 5.04$ and 94.15 respectively. Twenty subjects (25\%) reported a previous history of shoulder injury.

Conclusions: The Crossfit training appears to attract younger individuals, predominately male? With a high level of function related to upper extremity and shoulder joint. Future prospective longitudinal studies should examine improvement in function and rate of injury while on Crossfit training.

Keywords: Crossfit; Physical therapy; Shoulder; Epidemiology

\section{Introduction}

CrossFit, a recently popularized fitness regimen, currently has limited objective data reported in the scientific literature. The concept for CrossFit originated from a gym in Santa Cruz, California by Greg Glassman; this fitness regimen initiated its national network on May 1, 2003 with an internet blog that contained a date, a picture, and a Workout of the Day (WOD) [1]. Since then, CrossFit has rapidly increased in popularity on a national and international scale.

The founder of CrossFit, Greg Glassman, intended the fitness regimen to be comprised of "constantly varied, high-intensity, functional movement [2]," which is how CrossFit is commonly described at large [3]. Glassman further states that CrossFit is meant to utilize camaraderie, competition, and sport to provide and environment where individuals can exert an exercise intensity that is difficult to reach by other standard workout regimens [2].

Regardless of the intended framework of the training regimen, CrossFit's popularity and participation has increased and brought forth speculation within the scientific community regarding the possibility of CrossFit being associated with orthopedic injuries.

Currently, there is little to no evidence to support the direct link of CrossFit to orthopedic injuries. Several studies, however, report adverse incidents or suspected associations between CrossFit and various injuries. A case study by Joondeph in 2013 reported a twenty-five year old male who had a right retinal detachment that was suspected to be the result of an elastic band snapping and hitting the patient's right eye during a CrossFit workout [4]. Lu et al. stated that intense CrossFit workouts may have led to cervical internal carotid artery dissections in three patients, however, history of cervical trauma or other cardiovascular conditions were not considered in these patients [5]. Lastly, in 2014, Larsen and Jensen reported a case of rhabdomyolysis in a 35-year-old woman following three days of intense exercise that included kayaking and pull-ups in CrossFit [6].

Despite the various criticisms, other studies have reported on the benefits of participating in CrossFit. In 2012, O'Hara and colleagues stated that CrossFit may assist airmen in the Air Force to meet fitness standards and prepare for the diverse environment and physical demands of rapid deployments [7]. Additionally, in 2013, Smith and colleagues reported significant improvements in body fat percentage maximal aerobic capacity (VO2Max) and body composition after 10 weeks of CrossFit training $(\mathrm{P}<0.05)$, however a control group was not included in this study design [8]. Another study in 2014 by Partridge and colleagues reported on how perception of goals and motivation within CrossFit gyms may affect one's participation based on demographic variables [9]. Lastly, in 2014, Heinrich and colleagues found that subjects who participated in CrossFit training
Austin J Orthopade \& Rheumatol - Volume 4 Issue 2 - 2017 ISSN: 2472-369X | www.austinpublishing group.com

Franklin et al. (c) All rights are reserved
Citation: Skinner C, Franklin S, Chang J, Sum J, Groshen S and Hatch G. Demographics, Activity Level, and Shoulder Health History of Populations Participating in CrossFit: A Descriptive Analysis. Austin J Orthopade \& Rheumatol. 2017; 4(2): 1052. 
maintained enjoyment of the program and were more likely to continue participating [10].

Another study in 2011 by Bergeron and colleagues reported on both the positive and negative characteristics of extreme conditioning programs such as CrossFit within military personnel [11]. Positive attributes included camaraderie, teamwork, decreased body fat, increased muscle endurance and cardiovascular capacity, and functional movements and conditions that mirror the high demands of combat readiness [11]. Negative attributes included the conclusion that these types of extreme-conditioning programs do not adhere to appropriate and safe training guidelines that unsafe movements can result in acute injury, and a concern of overuse, overreaching, and overtraining [11]

With any training regimen, there are associated risks and benefits. However, risks and benefits associated with CrossFit remain uncertain. The authors seek to add foundational objective and normative data to the literature to facilitate progress toward a more global understanding of potential risks and/or benefits of CrossFit training.

The design and methods of this study are similar to what was performed by Hak and colleagues in 2013. Hak et al. investigated the prevalence of injury among current participants in CrossFit and distributed an anonymous online questionnaire that inquired participants on their general demographics, training programs, injury profiles, and supplement use. 97 of the 132 participants (73.5\%) reported injury during CrossFit training, and the total number of injuries within this cohort was reportedly 18612. Additionally, Hak and colleagues reported that the shoulder had the highest prevalence of injury (31.8\%), which accounted for $25.8 \%$ of total injuries reported by participants [12]. A study by Weisenthal et al. in 2014 investigating injury patterns in CrossFit demonstrated similar results, reporting the shoulder to have the highest injury rate [13]. Due to the consistent reports of shoulder injury in CrossFit participants, this study focuses on the prevalence of shoulder injury history prior to CrossFit training and shoulder health when participating in CrossFit for the first time [12-16]. The design of the current study is also similar to the reports of Heinrich and colleagues in 2014 [10]. This group of investigators examined the effects of group-based high-intensity functional training, (CrossFit), compared to moderate-intensity aerobic and resistance training on exercise initiation and reported the demographics of the 23 subjects that participated in the study. The categories of demographic reports differ from those of Hak and colleagues in that the current study did not include a measurement of body fat percentage [10].

As previously stated, there is currently a lack of evidence to allow the scientific community to understand the level of injury risk involved in CrossFit. The need for a more objective and evidencebased answer has prompted this investigation of a population of firsttime CrossFitters. This study is a descriptive analysis of a population seeking to participate in regular CrossFit training for the first time with the purpose of reporting on demographics, current and previous level of activity, and shoulder heath history. The results of this study may provide clinicians with an overview of self-reported health history of individuals initiating a CrossFit training program. This may also provide future researchers with normative data of newcomers to
Table 1: Demographics and anthropometrics.

\begin{tabular}{|l|l|}
\hline Age (in years) & $31.15 \pm 7.91$ \\
\hline Height (in meters) & $1.68 \pm 0.11$ \\
\hline Weight (in kilograms) & $72.60 \pm 13.85$ \\
\hline BMI (body mass index) & $25.61 \pm 4.08$ \\
\hline $\mathrm{n}=74$. & \\
\hline
\end{tabular}

CrossFit, particularly in regard to screening for shoulder health.

\section{Methods}

With written consent from the owner, subjects were recruited from a single CrossFit gym. Recruitment was based on inclusion/ exclusion criteria and informed consent was obtained by all subjects. Inclusion criteria consisted of participant's age of 18 to 50 years and the ability to read and comprehend the English language. Exclusion criteria included participant age less than 18 years or more than 50 years, as well as any previous participation in CrossFit.

Subjects who consented to the study were asked to complete three questionnaires prior to their first CrossFit session: (1) an originally designed Pre-Participation Questionnaire (PPQ), which inquired about personal demographics, previous shoulder and medical history, and physical activity based on the recommendations of the American College of Sports Medicine [17]; (2) the Disabilities of the Arm Shoulder and Hand (DASH); and (3) the Penn Shoulder Score (PENN). The DASH intends to assess the ability of a person to perform certain upper extremity activities, with scoring ranging from $0-100$, where a higher score indicates greater disability. The PENN aims to assess a person's function (0-60), pain (0-30), and satisfaction $(0-10)$ in regard to the shoulder, with total scores ranging from $0-100$, where a higher score indicates greater function, lower pain, and higher satisfaction. Both the DASH and PENN have demonstrated adequate to excellent test-retest reliability with overhead athletes and patients with various shoulder disorders $[18,19]$.

Averages, standard deviations, and percentages were calculated for the current data set.

\section{Results}

Seventy-nine subjects ( 37 males, 42 females) met the inclusion criteria and were enrolled. Seventy-four (94\%) of these 79 subjects completed the intake PPQ and DASH, while 66 (84\%) completed the PENN. The baseline demographic and anthropometric findings are outlined in table (Table 1). Upon intake, the mean scores for the DASH and PENN were $2.46 \pm 5.04$ and 94.15 respectively (Table 2). 20 out of 74 (27\%) of subjects reported a previous history of shoulder injury (Table 2). 31 out of 74 (42\%) of subjects reported that they participate in weekly athletic activities involving the shoulder (Table 2).

Table 2: Shoulder health and history.

\begin{tabular}{|l|c|}
\hline DASH & $2.46 \pm 5.04$ \\
\hline Penn-Shoulder Score & $94.15 / 100$ \\
\hline Previous Shoulder Injury(s) & $20 / 74(27 \%)$ \\
\hline Weekly Shoulder Activity (Prior to CrossFit) & $31 / 74(42 \%)$ \\
\hline Shoulder injury within 2 months of starting CrossFit & $2 / 74(2.7 \%)$ \\
\hline
\end{tabular}

DASH: Disability of the Arm Shoulder and Hand; $n=74$. 
Table 3: Shoulder injury Data.

\begin{tabular}{|c|c|}
\hline Category & $\begin{array}{l}\text { Percentage of Participants Reporting } \\
\text { Shoulder Injury History (\%) }\end{array}$ \\
\hline \multicolumn{2}{|c|}{ Number of Previous Shoulder Injuries } \\
\hline One injury & 75 \\
\hline Two injuries & 10 \\
\hline Five or more injuries & 5 \\
\hline \multicolumn{2}{|c|}{ First Previous Shoulder Injury } \\
\hline Less than one month ago & 5 \\
\hline 4 to 6 months ago & 15 \\
\hline 6 to 12 months ago & 70 \\
\hline \multicolumn{2}{|c|}{ Most Recent Previous Shoulder Injury } \\
\hline Less than one month ago & 30 \\
\hline 2 to 3 months ago & 5 \\
\hline More than one year ago & 50 \\
\hline \multicolumn{2}{|l|}{ Previous Imaging } \\
\hline No imaging & 50 \\
\hline Radiographs (X-rays) & 35 \\
\hline MRI & 20 \\
\hline MRI with contrast & 5 \\
\hline CT scan & 5 \\
\hline \multicolumn{2}{|l|}{ Imaging Revealed } \\
\hline Rotator cuff tear & 5 \\
\hline Dislocation/instability & 15 \\
\hline AC joint sprain & 5 \\
\hline Impingement & 5 \\
\hline Other & 15 \\
\hline \multicolumn{2}{|l|}{ Diagnosis By Specialist } \\
\hline Orthopedic Surgeon & 10 \\
\hline Physical Therapist & 2 \\
\hline General/family practitioner & 15 \\
\hline Internal medicine & 10 \\
\hline Other & 25 \\
\hline \multicolumn{2}{|l|}{ Surgical Procedures } \\
\hline Shoulder Stabilization & 5 \\
\hline Other & 5 \\
\hline
\end{tabular}

Of the 20 subjects who reported having a history of shoulder injury, 18 went on to report the number of previous shoulder injuries (Table 3). The timing, imaging findings/diagnosis, and other information in regard to these previous injuries are outlined in table (Table 3).

\section{Discussion}

The results of this paper describe demographics, current and previous level of activity, and shoulder health history of a convenience sample population choosing to participate in CrossFit training for the first time at a single site. These results may assist CrossFit gym operators and future researchers in understanding the demographics and health history of a typical population of newcomers to CrossFit.
In regard to the demographic data, the mean age of participants in the current study (31.95) was similar to that in the study by Hak et al. (32.3) and Weisenthal et al. (30-39) [12,13]. These consistent findings suggest that the sample in this study is an accurate representation, at least in regard to age, of the typical CrossFit participant.

While Hak et al. reported a shoulder injury prevalence of $31.8 \%$ in their cohort of 132 participants and Weisenthal et al. reported 21 shoulder injuries out of 84 total injuries in their cohort of 386 participants, pre-CrossFit shoulder injury history prevalence was not explicitly reported or elaborated on in either study $[12,13]$. The current study found a prior shoulder injury prevalence of $27 \%$ in a cohort of 74 individuals. History of prior shoulder injury may have some prognosticating or predictive value in determining individuals who may be at risk of developing an injury during CrossFit participation. This can demonstrate the importance of a preparticipation questionnaire, similar to what was used in this study.

While Weisenthal et al. included self-reported diagnoses in their study, these diagnoses were not determined by imaging or medical professionals as was reported in this study (Table 3) [13]. For example, dislocation/instability was reported as one of the most common diagnoses of previous shoulder injury in this study. This data may give more precise insight into type of shoulder injury commonly seen in pre-participation CrossFitters which could aid in developing more effective injury risk reduction strategies.

This study also reported baseline shoulder outcome measure scores (DASH, PENN) which was not investigated in any of the aforementioned studies. The average scores of 2.46 and 94.15 for the DASH and PENN, respectively, provide early normative data of baseline shoulder function in this population. This data could prove useful in future studies comparing shoulder function in CrossFitters at different stages of participation and of varying experience levels.

One limitation of this study is that a few subjects were unable to complete the PPQ immediately prior to their first CrossFit training session due to various time constraints. However, these subjects finished their questionnaire immediately following their first CrossFit training session. In regard to the sample itself, the limited number of subjects taken from a single site warrants caution when extrapolating these findings.

\section{Conclusion}

This baseline and normative data could aid future researchers in identifying specific demographics that may be at higher risk for developing shoulder injury when starting CrossFit. In turn, this information could help CrossFit gym operators and clinicians develop injury prevention strategies, as well as assist the scientific and global community in better understanding the risk-benefit ratio associated with particular style of training. Additionally, future research may be able to identify what categories of shoulder function are most affected by CrossFit training.

\section{References}

1. What is CrossFit?

2. Glassman G. Understanding CrossFit. CrossFit Journal. 2007; 56: 1-2.

3. Grier T, Canham-Chervak M, McNulty V, Jones BH. Extreme conditioning programs and injury risk in a US Army Brigade Combat Team. U.S. Army Med Dep J. 2013: 36-47. 
4. Joondeph SA, Joondeph BC. Retinal Detachment due to CrossFit Training Injury. Case reports in ophthalmological medicine. 2013; 189837.

5. Lu A, Shen $P$, Lee $P$, et al. CrossFit-related cervical internal carotid artery dissection. Emerg Radiol. 2015; 22: 449-452.

6. Larsen C, Jensen MP. Rhabdomyolysis in a well-trained woman after unusually intense exercise. Ugeskr. Laeg. 2014; 176: 25.

7. O'Hara RB, Serres J, Traver KL, Wright B, Vojta C, Eveland E. The influence of nontraditional training modalities on physical performance: review of the literature. Aviat Space Env Med. 2012; 83: 985-990.

8. Smith MM, Sommer AJ, Starkoff BE, Devor ST. Crossfit-based high-intensity power training improves maximal aerobic fitness and body composition. J Strength Cond Res. 2013; 27: 3159-3172.

9. Partridge JA, Knapp BA, Massengale BD. An investigation of motivationa variables in CrossFit facilities. J Strength Cond Res. 2014; 28: 1714-1721.

10. Heinrich KM, Patel PM, O'Neal JL, Heinrich BS. High-intensity compared to moderate-intensity training for exercise initiation, enjoyment, adherence, and intentions: an intervention study. BMC Public health. 2014; 14: 789.

11. Bergeron MF, Nindl BC, Deuster PA, Baumgartner N, Kane SF, Kraemer WJ, et al. Consortium for Health and Military Performance and American College of Sports Medicine consensus paper on extreme conditioning programs in military personnel. Curr Sports Med Rep. 2011; 10: 383-389.

12. Hak PT, Hodzovic E, Hickey B. The nature and prevalence of injury during CrossFit training. J Strength Cond Res. 2013.

13. Weisenthal B, Beck C, Maloney M. Injury Rate and Patterns Among CrossFit Athletes. Orthop J Sports Med. 2014; 2.
14. Tuite MJ, Turnbull JR, Orwin JF. Anterior versus posterior, and rim-rent rotator cuff tears: prevalence and MR sensitivity. Skeletal Radiol. 1998; 27 : 237-243.

15. Cowderoy GA, Lisle DA, O'Connell PT. Overuse and impingement syndromes of the shoulder in the athlete. Magn Reson Imaging Clin N Am. 2009; 17: 577 593.

16. Bodin J, Ha C, Petit Le Manac'h A, et al. Risk factors for incidence of rotator cuff syndrome in a large working population. Scand J Work Environ Health. 2012; 38: 436-446.

17. Garber CE, Blissmer B, Deschenes MR, Franklin BA, Lamonte MJ, Lee IM. American College of Sports Medicine position stand. Quantity and quality of exercise for developing and maintaining cardiorespiratory, musculoskeletal, and neuromotor fitness in apparently healthy adults: guidance for prescribing exercise. Med Sci Sports Exerc. 2011; 43: 1334-1359.

18. Alberta FG, ElAttrache NS, Bissell S, Mohr K, Browdy J, Yocum L, et al. The development and validation of a functional assessment tool for the upper extremity in the overhead athlete. Am J Sports. 2010; 38: 903-911.

19. Leggin BG, Michener LA, Shaffer MA, Brenneman SK, Iannotti JP, Williams GR Jr. The Penn shoulder score: reliability and validity. J Orthop Sports Phys Ther. 2006; 36: 138-151.
Austin J Orthopade \& Rheumatol - Volume 4 Issue 2 - 2017 ISSN: 2472-369X | www.austinpublishing group.com Franklin et al. () All rights are reserved
Citation: Skinner C, Franklin S, Chang J, Sum J, Groshen S and Hatch G. Demographics, Activity Level, and Shoulder Health History of Populations Participating in CrossFit: A Descriptive Analysis. Austin J Orthopade \& Rheumatol. 2017; 4(2): 1052 